those of the Krísurík sulphur mines, and the so-called "porcelain rock," a bed of very pure, white, and compact siliceous sinter or geyseritc, deposited by some long extinct boiling spring. It was not till the afternoon of the next day that the weather cleared up a little, and a long and patient watch from the top of a hill behind the light house was at length rewarded by the discovery of a dim spot on the horizon, which close observation through a good telescope showed to be the new island. It was quite invisible to the naked eye, but the light-keeper assured me that he had often seen it in clear weather, without a glass. When first seen, on July 29, its shape was that of a truncated cone with a slight depression on the top, and a considerable hollow half way down the slope on the north side.

On August 5 and 6 a series of violent earthquake shocks occurred, which shook and split the masonry of the lighthouse and damaged the lamps. For several days the new island was obscured by mist and rain, and when it again became visible its shape was considerably altered a large part of the slope on the south side had slipped down into the sea, where it now lies, forming two little hillocks close to the foot of the main mass, and leaving a steep face nearly perpendicular towards the bottom. On the north side there is shoal water extending some distance from the island. The length of the island is about one-

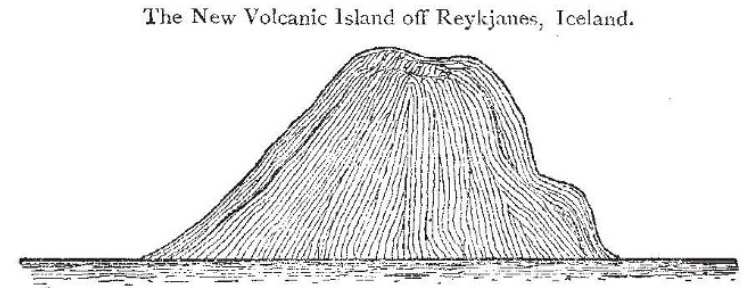

The island as when first seen,

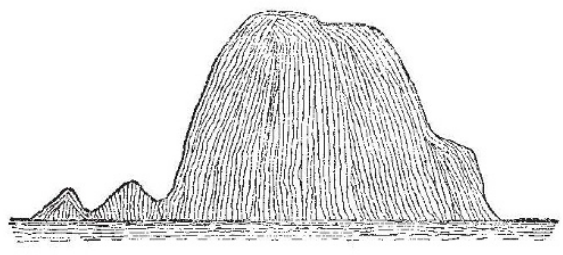

The island as it now appears.

third greater than its height. It lies nearly west-southwest of Reykjanes, and considerably to the north-west of Eldey. Two French naval officers who visited Reykjancs and made observations of the island about a fortnight before I arrived there, estimate its distance from the coast at nine or ten miles, but I believe it to be considerably greater. When first seen the island was perfectly black, but now the light-keeper tells me he can in clear weather distinguish by the aid of his glass a perceptible whitening of the upper part, due no doubt to the droppings of the myriads of sea-fowl which frequent the neighbouring islands and coast, and have apparently at once taken possession of the new island.

It is a singular fact that none of the ustal volcanic manifestations seem to have announced or accompanied the rise of the new island; no earthquakes were felt, no smoke or fire seen, and no pumice found floating on the sea. The island seems to have risen calmly and silently, without a soul being aware of its appearance, till, on July 29 , the light-keeper happening to look out to seaward, discovered it. For aught that any one knows to the contrary, it may have been there for many days before he happened to see it. No one has yet visited the island itself; the sea off Rekjanes is almost always rough, and the currents are very strong round the cape; the islands are surrounded by shoals and reefs; landing is at all times difficult and dangerous, even in the best weather, and quite impossible if the sea is at all disturbed; and as, since the discovery of the island, the weather has been for the most part stormy, intending explorers have been deterred by the dangers of the passage. Singularly enough, a French war-vessel and a Danish gun-boat which passed Reykjanes shortly before my visit failed to sec the new island. From the direction in which the new island lies, and its apparent distance from the coast, I am inclined to think that it must lie near to the Geirfuglasker (Gare-fowl Skerry), one of the four islands above mentioned, which lies somewhat to the north-west of the line formed by the other three, and which, being low and flat, cannot be seen from Reykjanes. It is not impossible that the new island is merely an addition to or upheaval of the old Geirfuglasker, which, by heightening it so as to make it visible from the shore, would produce the impression that a new island had risen. This view is held by some of the fishermen on the coast who are familiar with the islands, but the point cannot be definitely settled till the island is visited.

W. G. SPENCE PATERson,

British Consulate, Reykjavík, September 27

\section{TELESCOPES FOR ASTRONOMICAL PHOTOGRAPHY}

\section{I.}

BEFORE giving any suggestions as to the best kind of telescope to use, and the best methods to follow in the application of photography to astronomical observation and record, it may be more convenient to mention briefly what can be done in this way, particularly as the subject will be new to many who have not followed closely what has been recently done.

I wish to mention (I) That photography has now shown itself to be capable of giving us pictures of nebulæ that are superior to those made by eye and hand. (2) That anything that can be seen by the eye with a telescope of a certain size can be photographed, and, further than this, stars that are too faint to be seen in this telescope can yet be photographed by it with sufficient exposure. (3) That portions of the heavens of several degrecs extent each way can bc photographed, and stars therein of a magnitude smaller than that shown on the best existing charts or maps, pictured in their proper relative positions and magnitudes in a quicker, better, and more accurate manner than by the plan hitherto used. (4) That it is possible thus to make a complete serics of such pictures embracing the whole heavens, that will be practically free from human error. (5) That each individual nebula, cluster, or group of stars, can also be taken on as large a scale as possible, and form a supplement to the picture-maps on the smaller scale. (6) That though such pictures may differ slightly from the eye observations, owing to the different colours of light not affecting the eye and the sensitive plate in the same manner, they would have the cnormous advantage that they could be compared directly with other pictures, taken, after the lapse of any number of years, under conditions that there would be no difficulty in making almost identical. (7) That there are other applications of this new power, as in direct enlargements of the surface of the moon piece by piece, of the planets, of double stars, and close clusters, and indirectly in the discovery of planets, either major or minor, by the simple process of direct comparison of star pictures taken at intervals, when the actual position of a planet will be recorded at each date. If there be a planet beyond Neptune, such a plan as this is perhaps the only way to detect it, especially if it is now near the Milky Way, where stars of its probable magnitude cluster so thickly that no process other than this could be used to chart the stars and detect movement. If these things can be done, and I most 
confidently say they can, then it must be admitted that nothing short of a revolution in observational astronomy must result, to the enormous gain of astronomy.

I speak relying entirely on my own work and experiments, which I shall refer to in detail further on, and am strengthened in my opinions by what $I$ hear has been done in a similar direction elsewhere, though I have not, except in one case, seen any of the actual work done.

The possibilities that are thus opened out really border on the marvellous. As has been already said by some one else, a library may now be made, not of books full of descriptions and figures, the accumulated work of many men working many years, each on his own system, but of pictures written on leaves of glass by the stars themselves.

Such a work will mark an epoch in astronomy, and its value increase as long as astronomers exist. No one can doubt for one moment the importance of such a work, nor the fact that, now it is possible, any delay in doing it will be a direct loss to astronomy. How it is to be donewhether by the slow process of letting it be done by the disjointed efforts of many amateurs of astronomy, or by being properly taken in hand and finished by united effort and proper means in the course of a few years-remains to be seen.

I propose to make some suggestions as to the practical part of this work in the selection of the best kind of telescope and mounting, the methods of working, the work to be done, and some other matters in connection. The most important matter is no doubt the selection of the best instrument to work with: of the two kinds of telescopes now in use, the reflector seems to be the most suitable for this work, though a reservation may be made in favour of the refracting principle where large fields on a small scale are required. Both kinds of telescopes when of moderate dimensions, that is, not more than 18 inches aperture, are so nearly alike as optical instruments that the chief distinction worth noting, neglecting for the present one or two points where they differ, and altogether such points as are rather matters of individual prejudice on the part of the observer than qualities or defects in the instruments, is that of cost, the reflector being very much less expensive to make. It is true that the refractor has been hitherto generally considered the most satisfactory in use, and has been preferred when expense has not been a consideration of importance. I think this may be rather due to the greater care that is bestowed upon the more expensive instrument, both in the making of the object-glass and the mounting, than to any real difference that there is between them. The first cost of the raw material alone differs immensely. For the reflector one disk of glass alone is required, and if it is only properly annealed it need not be optically pure. There is only one surface to work, though it is of importance that this should be properly figured, this is not a difficult matter, yet there is little doubt it has often been very imperfectly done in many so-called reflecting telescopes.

For the refractor two disks of glass are required ; they must be optically pure, and their first cost alone is more than is often spent on the reflector, including the mounting. These disks must be wrought on four surfaces to proper curves, and time often spent afterwards in perfecting the object-glass; when this is done, the cost is found to be so great that it is felt to be worth a costly mounting. We cannot then be surprised that the better made and mounted telescope should be chosen, but that does not decide the question, Which is the best optical instrument? Nor can this question be decided definitively, because the images formed by each differ. If we look with a reflector at a bright star, the image is seen as an intensely bright point of light, dazzling to the eye if the telescope is large, and we see rays or coruscations round it of an irregular shape that are never steady. I think this effect is not due to the telescope, but is entirely subjective, and caused by this extremely small point of light exciting only a very small portion of the retina; for by proper precautions the light can be reduced, and these rays and the dazzling effect got rid of. With stars less bright it is not so pronounced, and on planets or objects of sensible magnitude it ceases entirely. The image of such a bright star in the refractor is quite of another kind: it is seen as a small disk of light of sensible diameter surrounded by the well-known system of diffraction rings and outstanding colour. This disk of light though small, has a different effect on the retina: it can be seen as a shape, pretty steady and free from too much dazzling glare. It is here that the refractor has such an advantage for micrometrical work, permitting bisections to be made with such precision.

The adjustments of the object-glass are considered more constant than those of the speculum, and though the troubles attending the reflector are much exaggerated, they have existed in the arrangements usually adopted. For certain instruments such as the transit-circle, where the connection between the optical axis and some part of the instrument has to be maintained, the object-glass is superior to the speculum; a tilt of the former that would not have an appreciable effect on the position of the image of a star would in the other displace this image twice the amount of tilt.

Both kinds have certain advantages, according to the use they are put to, and it is really not of much consequence which is the best instrument of this size. It is when we begin to consider the effect of increased size and all its attendant difficulties that the question of the suitability of either for the purpose of photography has to be answered.

With the reflector increase of size means proportionate increase in other qualities, in light-grasping power, in defining, and in separating power. With the refractor the greater absorption of light due to increased thickness reduces the light-grasping power, and definition becomes a matter depending not upon the optician but upon the glass-maker; the correction for colour, which even in theory is approximate only, becomes more difficult, and the defects due to the necessarily imperfect correction become more apparent-and these two facts alone show that as the refracting telescope gains in size it becomes more and more unsuitable for photography.

Moreover, when the aperture of the two kinds of telescopes under consideration is the same, the focal length of one must be something like twice that of the other, and that means that the image is four times less bright, and there does not seem to be any indication that the focal length of refractors can be very much reduced. This is only one part of the question, the next and most important one is that of actual cost or difficulty of construction. In the case of the refractor the preliminary difficulty in getting the lumps of glass out of which the lenses have to be made is so great that the increase of the sizc beyond 30 inches seems at the present moment very doubtful-they may reach 3-foot, or even 4 -foot aperture, but it is most unlikely : the cost alone, good or bad, would be simply enormous, and such a size may be for the present left out of consideration. With the reflector the case is entirely different: from what has been said, it is easy to see that the gain by increase of size is proportionate here, and that only mechanical difficulties have to be met. Mirrors of glass covered or coated with silver for the reflecting surface are now in existence of 3- and 4-foot aperture; larger are in hand, and can be made at a cost absurdly below the cost of even a possible refractor: the only limit that I can see here is that of glass, and the limit in this case stops not at 30 inches, as with the refractor, but at something like 70 inches, and that and nothing else of a constructive character prevents the reflector being made much larger, and size is a great 
thing in photography. It is, in the case of eye-observation, a fact that you could positively have a telescope too big for the eye to use, but any increase that is at present possible in the reflector would only add to its photographic power.

The optical arrangements of the reflector are so varied that I propose to treat of them in detail for the purpose of indicating the most suitable. A. AinsLie COMMON

\section{NOTES}

THE following is the list of officers, \&c., to be proposed at the anniversary meeting of the Royal Society, December I, I884 :President, Prof. Thomas Henry Huxley, LL.D. Treasurer, John Evans, D.C.L., LL.D. Secretaries: Prof. George Gabriel Stokes, M.A., D.C.L., LL.D., Prof. Michael Foster, M.A., M.D. Foreign Secretary, Prof. Alexander William Williamson, LL.D. Other Members of the Council : Capt. W. de Wiveleslie Abney, R.E., William Henry M. Christie, AstronomerRoyal, Prof, Georgc H. Darwin, M.A., F.R.A.S., Warren De La Rue, M.A., D.C.I., Robert Etheridge, F.R.S.E., F.G.S., Sir Frederick J. O. Evans. K.C.B., Prof. William Henry Flower, LL.D., Prof. George Carey Foster, B.A., Sir Joseph D. Hooker, K.C.S.I., Prof. Henry N. Moseley, M.A., F.L.S., Hugo Miiller, Ph.D., Capt. Andrew Noble, R.A., C.B., Lord Rayleigh, D.C.L., Prof. J. S. Burdon Sanderson, LL.D., Lieut.-Gen. R. Strachey, R.E., C.S.I., Prof. J. J. Sylvester, M.A., I.C.L., I.I..D.

Prof. Liversidere, of the Sydney University, sends to the local press a suggestive comrunication in connection with the recent meeting of the Briti:h Association in Montreal, and the invitation forwarded by the Victorian Premier to visit Melbourne next year. Feeling how insurmountable for the present are the obstacles to such a visit, the writer propo:es what appears to be a very wise alternative. Instead of looking forward to a near visit from the Association, he suggests, as a preliminary step, a federation of the various scientific societies in Australia, Tasmania, and New Zealand into an Australasian Association for the Advancement of Science on the lines of the British Association. A first meeting of the new $\Lambda$ ssociation might be beld in Sydney on the hundredth anniversary of the colony, which with the combined attractions of an International Exhibition might induce a fair number of scientific visitors from England to take part in the proceedings. After the first meeting gatherings could take place annually, or every two or three years, as might be agreed upon by the members, in various parts of Australasia. The writer concludes with the remark, which few will gainsay, that such an Association would tend greatly to advance the sciences in the colonies, and in many ways materially favour their progress elsewhere.

AcCording to Sience, Prof. E. S. Holden, Director of the Washburn Observatory of the University of Wisconsin, has lately collected all the data available for the discussion of the law of distribution of the fixed stars, so far as this is determinable from the method of star-gauging. The data were $\mathrm{c}$ llected from a com. parison with the results of a series of star-gauges in progress with the 15 -inch equatorial of the Washburn $\mathrm{Ob}$ :ervatory ; and they included (I) the 68,3 previously published gauges of Sir W. Herschel, with the places brought down from 1690 to $x 860$; (2) the 405 unpublished gauges of Sir W. Herschel, extracted from his observing-books, and generously placed at Prof. Holden's disposal by Lieut.-Col. John Herschel (these also reduced to I860); (3) 500 counts of stars from the published charts of Dr. C. H. F. Peters ; (4) 983 counts of stars from the unpublished charts of Dr. Peters, from the Paris charts as revised by him, and from the unpublished celiptic charts of Prof. Watson ; (5) 856 counts of stars from the unpublished and published charts of Dr. J.
Palisa. These, with the data from Sir J. Herschel's 605 southern gauges, and Celoria's Durchmusterung of the stars between $0^{\circ}$ and $+6^{\circ}$, complete the very valuable callection of data which Prof. Holden has brought together in convenient tabular form, and from which one of his most important conclusions is, that the method of star-gauging must be applied to the study of comparatively small regions, and that the results from these are then to be combined into larger groups. Prof. Holden hopes that these tables may serve the valuable end of finally disposing of the fundamental assumption that the stars are equally scattered in space, and may bring about the study of their distribution on a more general basis.

THE Boston Society of Natural History have adopted a policy with regard to their library which, if generally followed, would make scientific libraries more generally useful. The Society send such books as can be replaced to students in any part of the country. The receivers of course pay the cost of carriage, and, in addition, strangers are requircd to deposit a sum equal to twice the market-value of the books so lent, as a guarantee against loss.

A BUREAU of scientific information has been formed in Philadelpbia, composed of officers and members of the Academy of Science, whose duty shall be the imparting, through correspondence, of precise and definite information upon the different departments of science. The organisation is purely voluniary. The Sccretary is Prof. Angelo Heilprin, of the Academy of Science.

THE new buildings of the Central School at Paris were opened last week by M. Rouvier, the new Minister of Commerce and Agriculture. A number of speeches were delivered on the occasion, from which we learn that as many as 5000 French engineers owe their training to this institution since its foundation fifty years ago by the late M. Dumas and others. The object contemplated by the erection of this institution was to check the predominatingly theoretical character of the instruction imparted by the Government schools and to remodel the engineering education in France according to the English standard. About ten years ago the establishment was purchased by the Government, but the teachers have held as closely as possible to the lines on which its teaching was originally laid down.

Mr. STANFORD, of Charing Cross, has issued a reprint of the paper on the Ethnology of Egyptian Sudán, contributed by Prof. A. I. Keane to the November number of the Fournal of the Anthropological Institute. This monograph, which will be welcome to all interested in the eventful drama now in progress in the Nile Valley, contains a summary but comprehensive survey of all the races between Egypt and the Equator, which are grouped in five main divisions: Bantu, Negro, Nubian, Semitic, and Hamitic. Much light is thrown on the obscure relations of thesc peoples to each other, and a clear picture presented to the reader of the manifo!d ethnical conditions in those regions. The tabulated schemes of all the Sudánese races with their numcrous subdivisions, seem to be very complete, and will help to a better understanding of the reports daily received from the scene of the operations undertaken for the relicf of Gen. Gordon and the Egyptian garrisons in the Sudan.

Trie first annual meeting of the New England Meteorological Society was held in Boston on the 21st ult. The papers read were:-On rain-gauges, by Mr. Fitzgerald; rainfall maps, by Mr. Davis; weather obscrvers in New England, by Prof. Upton; the establishment of a meteorological station on Blue Hill, Mass., by Mr. Rotch.

Witir reference to our recent note to the effect that Prof. Hugo Gyldén, Director of the Stockholm Observatory, had 